\title{
Effect of Variable Compression Ratios on Performance and Emission Phenomena of DI CI Engine Fuelled with Palm Stearin Biodiesel-Diesel Blends
}

\author{
V. Hariram**, N. Balakarthikeyan*, S. Seralathan** and T. Micha Premkumar* \\ *Department of Mechanical Engineering, Hindustan Institute of Technology \& Science, Hindustan University, \\ Chennai, India \\ **Department of Aeronautical Engineering, Hindustan Institute of Technology \& Science, Hindustan University, \\ Chennai, India \\ $\dagger$ Corresponding author: V. Hariram; connect2hariram@gmail.com
}

\author{
Nat. Env. \& Poll. Tech. \\ Website: www.neptjournal.com \\ Received: 27-05-2020 \\ Revised: 25-06-2020 \\ Accepted: $25-07-2020$ \\ Key Words: \\ Palm stearin wax \\ Transesterification \\ Biodiesel \\ Engine performance
}

\begin{abstract}
Rapid depletion of fossil fuels and escalating crude oil prices led the researchers to ascertain alternative feedstock as a substitute for mineral diesel. Biodiesel produced from non-edible sources was one among them. In the present investigation, palm stearin wax, a residue of palm oil extraction was used as a value-added feedstock for the production of biodiesel. Palm stearin biodiesel (PSBD) was derived from this feedstock using single stage transesterification process involving methanol and sodium hydroxide as a catalyst. PSBD was blended with mineral diesel at 20\% (D80PSBD20) and $50 \%$ (D50PSBD50) in volume basis. The effect of variable compression ratios on the performance and emission phenomena of direct injection $\mathrm{Cl}$ engine was analysed for test fuel blends. The tests were carried out for compression ratios 17:1, 17.5:1 and 18:1. Among all the fuel blends, D80PSBD20 blend showcased better performance characteristics along with reduced exhaust emissions at compression ratio of $18: 1$.
\end{abstract}

\section{INTRODUCTION}

The increase in usage of internal combustion engine based automobile vehicles led to a dramatic increase in the demand for fossil fuels. Due to the escalating crude oil price and reduced availability of the fossil fuels led to explore the usage of vegetable-based bio-oil as a substitute fuel for compression ignition (CI) engine in the mid-1930s. The use of straight vegetable oil in $\mathrm{CI}$ engine created drastic deterioration on the engine's performance due to enlarged molecular size, higher density and increased kinematic viscosity (Arcaklioglu \& Celikten 2005). Detailed investigations were conducted to reduce the kinematic viscosity of vegetable oils which includes heating, thermal cracking, transesterification, pyrolysis and others. Among these approaches, transesterification process emerged as a feasible and cost-effective methodology. According to pollution and renewable sources, the production capacity of biodiesel was getting increased day by day. Biodiesel was extracted from the feedstocks of either edible or non-edible oils. As the demand for edible oil for the cooking purpose already exists, non-edible oils were seen as the prime source for the production of biodiesel (Hariram et al. 2018). In the transesterification process, the mono-alkyl esters are converted into fatty acid methyl esters. Biodiesel produced from waxes is classified into two, such as animal waxes and plant waxes. Therefore, the palm stearin biodiesel extracted from the feedstock of the palm stearin wax obtained from palm oils is grouped as a plant wax. Based on the free fatty acid (FFA) content, the transesterification process is grouped into single-stage transesterification and double stage transesterification. As the FFA content of the palm stearin bio-oil was below two, single-stage transesterification was carried out to produce palm stearin biodiesel (Canakci et al. 2006). In general, three parameters influence the yield of biodiesel namely catalyst concentration, methanol to oil molar ratio, and reaction duration and these parameters were optimized to produce optimal yields. Ahmad et al. (2019) reported on the biodiesel production by transesterification process from flaxseed oil with a yield of $99.5 \%$. The yield was determined at an optimum catalyst concentration, molar ratio and reaction duration of $0.51 \%$ catalyst, 5.9:1 and 33 minutes respectively. Anand et al. (2019) reported an optimum yield of biodiesel using Indian sardine fish as feedstock. The yield was $96.57 \%$ for process parameters namely, 20 vol. $\%$ methanol, $1.25 \mathrm{wt}$ $\% \mathrm{KOH}$ and reaction duration of 25 minutes. The characterization was also done using the GC-MS analysis.

Compression ratio (CR) is one of the key performance parameters for the $\mathrm{CI}$ engine. $\mathrm{CR}$ is responsible for the peak in-cylinder pressure and temperature during the combustion 
of the hydrocarbon fuel. The variation of CR from the factory set value significantly affects the combustion, performance and emission phenomenon of the CI engine. Rosha et al. (2019) reported the combustion, performance and emission characteristics on $\mathrm{CI}$ engine with varying compression ratio using the palm-biodiesel blend. Palm-biodiesel B20 blend gave an optimal performance characteristic on increasing the compression ratio up to $18 \mathrm{CR}$. The increase in CR reduced the $\mathrm{CO}, \mathrm{HC}$ and smoke emissions to $47.8 \%, 41.0 \%$ and $35.7 \%$ respectively but increased the NOx emission to 41.1\%. Mustafa et al. (2009) observed that the performance and emission of an engine fuelled with frying palm oil led to a better performance and emission values as predicted by ANN.

Ganesh et al. (2018) studied the emissions of palm stearin biodiesel involving six different blends namely, B20, B40, B60, B80 and B100. Palm stearin biodiesel reported lesser emissions ( $\mathrm{HC}, \mathrm{CO}, \mathrm{CO}_{2}, \mathrm{NO}_{\mathrm{x}}$ and smoke) compared to diesel. Hosamani \& Katti (2018) studied the combustion, performance and emission characteristics of variable compression ratio (VCR) direct injection (DI) CI engine fuelled with Simarouba and Jatropha oil at various compression ratios and load conditions. Saravanan et al. (2019) analysed the performance and emission characteristics of VCR DI CI engine fuelled with rapeseed and Madhuca biodiesel blends. Anantha Kumar et al. (2016) investigated the performance and emission characteristics of VCR engine fuelled with diesel, waste plastic oil blended fuels with three blends such as $2.5 \%, 7.5 \%$ and $12.5 \%$. The brake thermal efficiency enhanced by increasing the CR from 12CR to $20 \mathrm{CR}$.

Raheman \& Ghadge (2007) investigated the emission and performance characteristics of Madhuca indica biodiesel blends fuelled in Ricardo E6 engine. The investigation re- vealed that B20 blend was a suitable alternative to control air pollution. Praveena et al. (2020) analysed the performance and emission characteristics of DI CI engine fuelled with the grapeseed biodiesel blends. The test was conducted with various load conditions to predict the emissions of $\mathrm{CO}, \mathrm{NO}_{\mathrm{x}}$, $\mathrm{CO}_{2}, \mathrm{HC}$ and smoke. The UBHC got reduced by $20.7 \%$ compared to diesel fuel.

On reviewing the literature, it was observed that fuel sourced from non-edible feedstocks proved to be a promising substitute for the mineral diesel fuel. Numerous researchers have proved the utility on the usage of vegetable-based biodiesel in CI engines, but its effect on varied compression ratio needs exploration. In this study, palm stearin wax, derived as a residue during the extraction of palm oil, was used as a potential feedstock for biodiesel production. The palm stearin wax oil was subjected to a single stage transesterification process to transform it as palm stearin biodiesel (PSBD). PSBD was blended with mineral diesel in various proportions and its effect on the performance and emission phenomenon was analysed. Furthermore, the influence of the variations of the compression ratio on the emission and performance characteristics was studied.

\section{MATERIALS AND METHODS}

\section{Materials}

Palm stearin wax residue obtained after palm oil extraction was purchased from a local vendor in near Ambattur in the city of Chennai, Tamil Nadu, India. To carry out transesterification process, $99 \%$ pure sodium hydroxide and laboratory-grade methanol were procured from Praxor Scientific Corporation, Chennai and Hydrova Chemical and Systems,
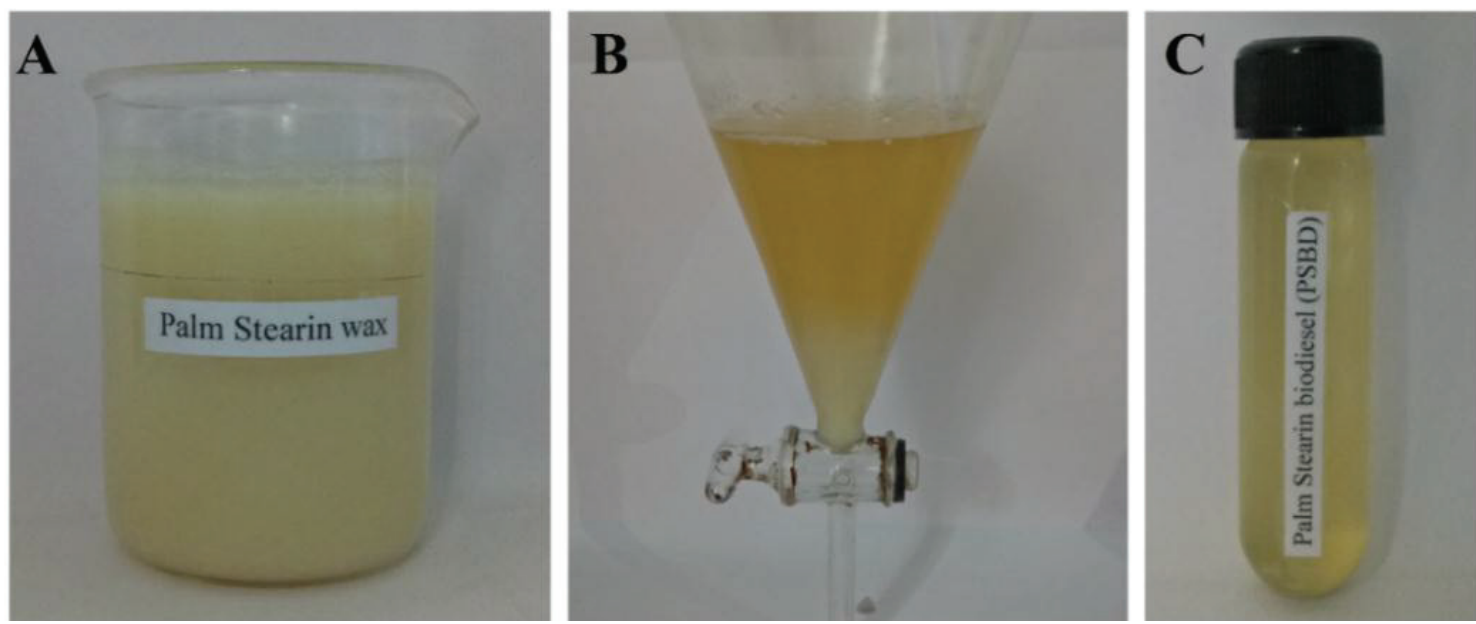

Fig 1: Bio-oil feed stock and PSBD. 
Chennai respectively. Mineral diesel was purchased from a local petrol refilling station. All the chemical reagents procured were of analytical grade. Whatman's filter paper was procured from Swastik Scientific Company, Chennai, India to filter the biodiesel obtained during the transesterification process.

\section{Biodiesel Production}

Using titration method, the acid value of palm stearin wax oil was found to be 1.72 . Therefore, single stage transesterification process using sodium hydroxide and methanol was adopted as it was widely reported by many researchers for the conversion of bio-oil with lower free fatty acid content into biodiesel. The transesterification process was carried out at Antonin Lavoisier Laboratory, Hindustan Institute of Technology and Science, Chennai, India. Initially, the palm stearin wax oil (Fig. 1A) was preheated upto $60^{\circ} \mathrm{C}$ and allowed to react with known concentrations of methanol and sodium hydroxide. The chemical reaction and the catalytic change in the reaction chamber were recorded carefully. On analysing the obtained data, it was noticed that the optimum conditions for biodiesel formation were 6:1 methanol to oil molar ratio, $62^{\circ} \mathrm{C}$ reaction temperature and 70 minutes of reaction time. The transesterification process was initiated using two litres inverted round bottom conical flask with holder arrangement.

Firstly, $0.72 \%$ of sodium hydroxide was thoroughly mixed with $400 \mathrm{~mL}$ of methanol for 20 minutes and kept at an agitation speed of $350 \mathrm{rpm}$ for the formation of sodium methoxide solution. $500 \mathrm{~mL}$ of palm stearin wax oil heated up to $65^{\circ} \mathrm{C}$ for 45 minutes and later blended with sodium methoxide solution. The solution was agitated for $60 \mathrm{~min}-$ utes at $450 \mathrm{rpm}$ during which the reaction temperature was maintained between $65^{\circ} \mathrm{C}$ and $70^{\circ} \mathrm{C}$. Then, the entire mixture was transferred into an inverted conical flask and a settling period of 12 hours was allowed. After six hours of settling, a ring formation appeared which separated the palm stearin biodiesel from glycerol. After 12 hours, the lower knob of the settling flask was opened to remove the glycerol (Hariram et al. 2015). The palm stearin biodiesel (PSBD) thus obtained was washed thoroughly with distilled water to remove the presence of methanol and glycerol. Later, the PSBD solution was heated up to $75^{\circ} \mathrm{C}$ to remove any moisture content. By the approach, $92.5 \%$ of palm stearin biodiesel was obtained (Fig. 1C).

\section{Physio-chemical Properties of Test Fuels}

Palm stearin biodiesel and its fuel blends were assessed for its physicochemical properties namely density, calorific value, kinematic viscosity, flash and fire point (Table 1). The density of PSBD was reduced to $0.882 \mathrm{~g} / \mathrm{m}^{3}$ from $0.941 \mathrm{~g} / \mathrm{m}^{3}$ at $15^{\circ} \mathrm{C}$ through transesterification process. The kinematic viscosity also showcased a significant reduction from 5.27 $\mathrm{mm}^{2} / \mathrm{s}$ to $2.41 \mathrm{~mm}^{2} / \mathrm{s}$ at $35^{\circ} \mathrm{C}$. The calorific value showed a substantial increase up to $37122 \mathrm{~kJ} / \mathrm{kg}$ from $21543 \mathrm{~kJ} / \mathrm{kg}$. The high flash and fire point values as $164^{\circ} \mathrm{C}$ and $242^{\circ} \mathrm{C}$ respectively reduced volatility of the PSBD. Table 1 lists the properties of PSBD which was compared with mineral diesel and other test fuel blends to understand its suitability in CI engine and all met the expected ASTM D6751 standards (Hariram et al. 2016).

\section{Experimental Procedure}

The experimentations were conducted at the standard operating condition and the average of three trials was used to analyse the test results. The test fuel blends used in this experiment were mineral diesel (100\% commercial diesel), D80PSBD20 (mixture of $80 \%$ mineral diesel and $20 \%$ of PSBD) and D50PSBD50 (mixture of 50\% mineral diesel and 50\% PSBD). All the test fuel blends were prepared on the volume basis in a separate conical flask with almost care and agitated for 20 minutes to ensure thorough mixing of the test fuels.

Fig. 2 represents the layout of the experimental setup. Table 2 portrays the technical specification of the test engine. The performance and emission test of various fuel blends were carried out using Kirloskar 240 PE, 4-stroke, constant speed (1500rpm), water-cooled, computerized DI CI engine equipped with an eddy current dynamometer. Calibrated transmitters were used to restrain the air and fuel flow. Cali-

Table 1: Comparison of test fuel properties.

\begin{tabular}{|lllll|}
\hline Properties & Palm stearin wax oil & $\begin{array}{l}\text { Palm stearin biodiesel } \\
\text { (PSBD) }\end{array}$ & $\begin{array}{l}\text { Mineral die- } \\
\text { sel }\end{array}$ & D80 PSBD20 \\
\hline Density @ $15^{\circ} \mathrm{C}\left(\mathrm{g} / \mathrm{m}^{3}\right)$ & 0.941 & 0.882 & 0.832 & 0.841 \\
Kinematic viscosity @ $35^{\circ} \mathrm{C}\left(\mathrm{mm}^{2} / \mathrm{s}\right)$ & 5.27 & 2.41 & 2.57 & 2.45 \\
Calorific value $(\mathrm{kJ} / \mathrm{kg})$ & 21543 & 37122 & 42955 & 40329 \\
Flash point $\left({ }^{\circ} \mathrm{C}\right)$ & - & 164 & 48 & 127 \\
Fire point $\left({ }^{\circ} \mathrm{C}\right)$ & - & 242 & 140 & 168 \\
\hline
\end{tabular}


brated thermocouples were used to measure the temperature. Load on the engine was measured using a load cell. Rotameter was used to measure the flow of water. The tests were performed on three parameters namely compression ratios, fuel blends and various loads. Initially, the investigation was carried out using diesel as fuel at different load conditions.

The outcomes obtained by diesel fuel at different compression ratios and load conditions formed the baseline for further tests using different test fuels. The engine was run for 5 minutes to accomplish a constant operating condition which was the pertinent condition to run the engine. The load test was conducted by changing the loads from no load to full load (i.e., no load, low load, part load and full load conditions). Moreover, the test was conducted at various compression ratios, i.e. 17:1, 17.5:1 and 18:1 with varied fuel blends and diesel at various load conditions. The compression ratio was changed using the tilting block arrangement during the engine operation. Engine load was increased from low load to high load and then decreased from high load to low load to maintain the compression ratios and investigations of repeatability. The exhaust gas analyser was used to analyse emissions namely, $\mathrm{CO}, \mathrm{HC}, \mathrm{CO}_{2}$, and $\mathrm{NO}_{\mathrm{x}}$ and the smoke meter was used to measure smoke opacity. The square root technique was used to predict the overall uncertainty of the experiments conducted and it was $1.89 \%$ as shown below.

Overall uncertainty (UC) = square root of (uncertainty of BSFC $)^{2}+(\text { uncertainty of BTE })^{2}+$ (uncertainty of $\mathrm{BP})^{2}+(\text { uncertainty of } \mathrm{CO})^{2}+($ uncertainty of $\left.\mathrm{NO}_{\mathrm{X}}\right)^{2}+(\text { uncertainty of } \mathrm{HC})^{2}+(\text { uncertainty of smoke })^{2}$ $=1.89 \%$

\section{RESULTS AND DISCUSSION}

\section{Performance Characteristics}

Brake thermal efficiency: Fig. 3 depicts variations of brake thermal efficiency at various compression ratios for different load conditions involving fuel blends D80PSBD20, D50PSBD50 and mineral diesel. The brake thermal efficiency (BTE) of all test fuels was observed to be low at no-load conditions for the case $17.5 \mathrm{CR}$. As the load is increased to part load, the BTE of all the blends increased. This may be due to an increase in the prevailing combustion temperature inside the combustion chamber. Fig. 3 portrayed that $17.5 \mathrm{CR}$ showed a higher value of BTE for all blends at full load conditions in comparison with other compression ratios. At $17.5 \mathrm{CR}$, the maximum BTE $(41.8 \%)$ was produced by diesel fuel at full load condition. This is due to its high calorific value $(45.5 \mathrm{MJ} / \mathrm{kg})$, lower density, high viscosity and good air-fuel mixture ratio leading to complete combustion within the combustion chamber. At 17.5CR, the D50PSBD50 fuel blend showed a lower BTE value which was due to its fuel density, viscosity and calorific value phenomenon. Later, the compression ratio was reduced to $17 \mathrm{CR}$ and the BTE values of all fuel blends decreased at no-load conditions with respect

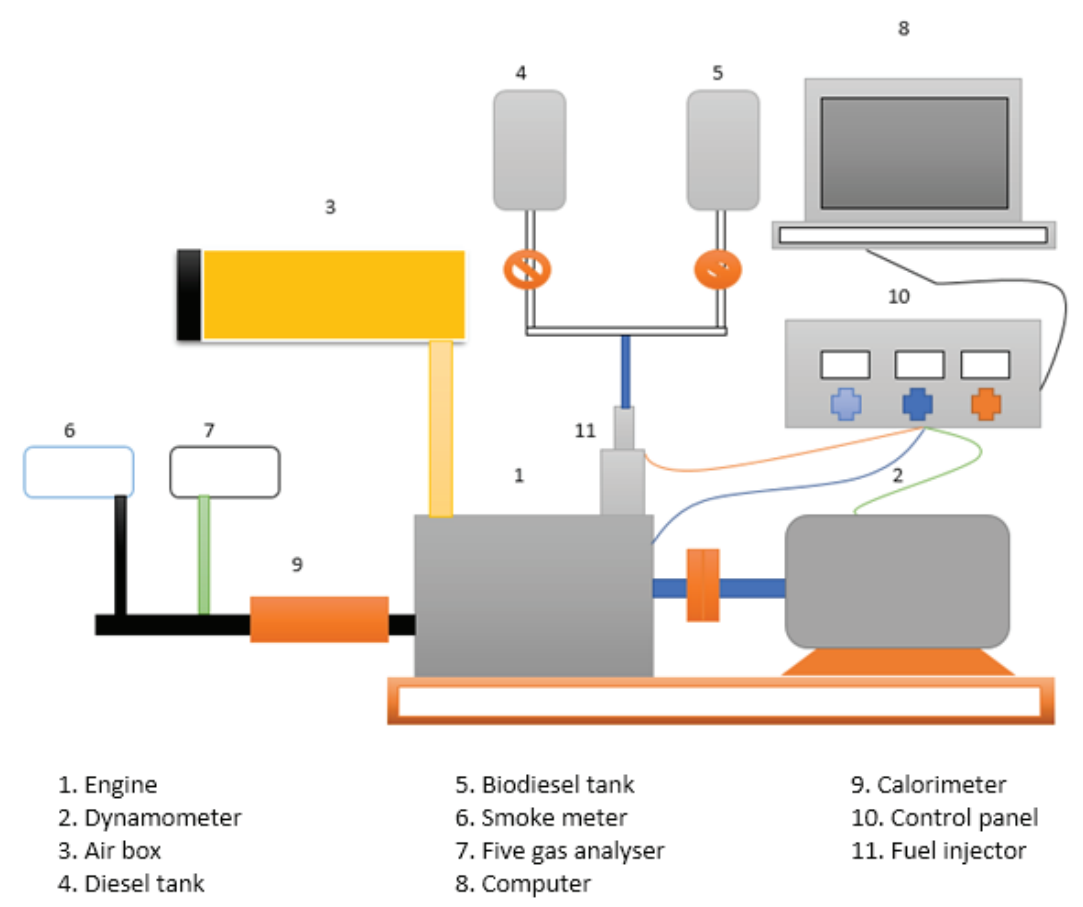

Fig. 2: Experimental setup. 
Table 2: Test engine specification.

\begin{tabular}{|ll|}
\hline Model and Make & $240 \mathrm{PE} /$ Kirloskar make \\
\hline Stroke & $110 \mathrm{~mm}$ \\
Bore & $87.5 \mathrm{~mm}$ \\
Factory set Compression ratio & 17.5 \\
Loading & Eddy current dynamometer \\
Rated power & $3.5 \mathrm{~kW} @ 1500 \mathrm{rpm}$ \\
Injection timing & $23^{\circ} \mathrm{bTDC}$ \\
Swept volume & $661.45 \mathrm{cc}$ \\
\hline
\end{tabular}

to $17.5 \mathrm{CR}$. This demonstrated the incomplete combustion phenomena with lower combustion temperature at low load conditions. Augmentation of the engine loading led to an increase in the combustion temperature and D80PSBD20 blend produced peak BTE. Similarly, BTE of all fuel blends at all load conditions increased on increasing the compression ratios to $18 \mathrm{CR}$. This may be due to a decrease in combustion chamber volume leading to an increase in temperature within the combustion chamber. At 18CR, BTE of the D80PSBD20 and D50PSBD50 increased at low load with other CR ratios. At full load conditions, D80PSBD20 blend gave a better BTE at $18 \mathrm{CR}$ as $41.79 \%$ which was due to high combustion temperature within the combustion chamber. Higher blend (D50PSBD50) possessed low calorific value, lower combustion temperature, lower atomization and high density leading to poor brake thermal efficiency (Cenk et al. 2011).

Brake specific fuel consumption: The variations of brake specific fuel consumption (BSFC) at various engine loads for test fuels namely mineral diesel, D80PSBD20 and D50PSBD50 are presented in Fig. 4. Irrespective of the compression ratios, the BSFC were higher for all fuel blends at low load conditions. BSFC was inversely proportional to the brake thermal efficiency. Upon increasing the load condition up to the part load, the BSFC of biodiesel blends decreased significantly. D80PSBD20 gave the least BSFC $(0.27 \mathrm{~kg} / \mathrm{kWh})$ among blended fuel for $17.5 \mathrm{CR}$ at all load conditions. This may be due to lower density and complete combustion in the combustion chamber. D50PSBD50 blend showed high BSFC values at all load conditions which may be due to low combustion temperature within the combustion chamber. Also, its density was high and calorific value was low compared to D80PSBD20 blend. Upon increasing the load to part load and later to full load condition, the BSFC values decreased representing an increase in the combustion temperature inside the combustion chamber. At 17CR, the mineral diesel gave a better BSFC value of $0.27 \mathrm{~kg} / \mathrm{kWh}$.

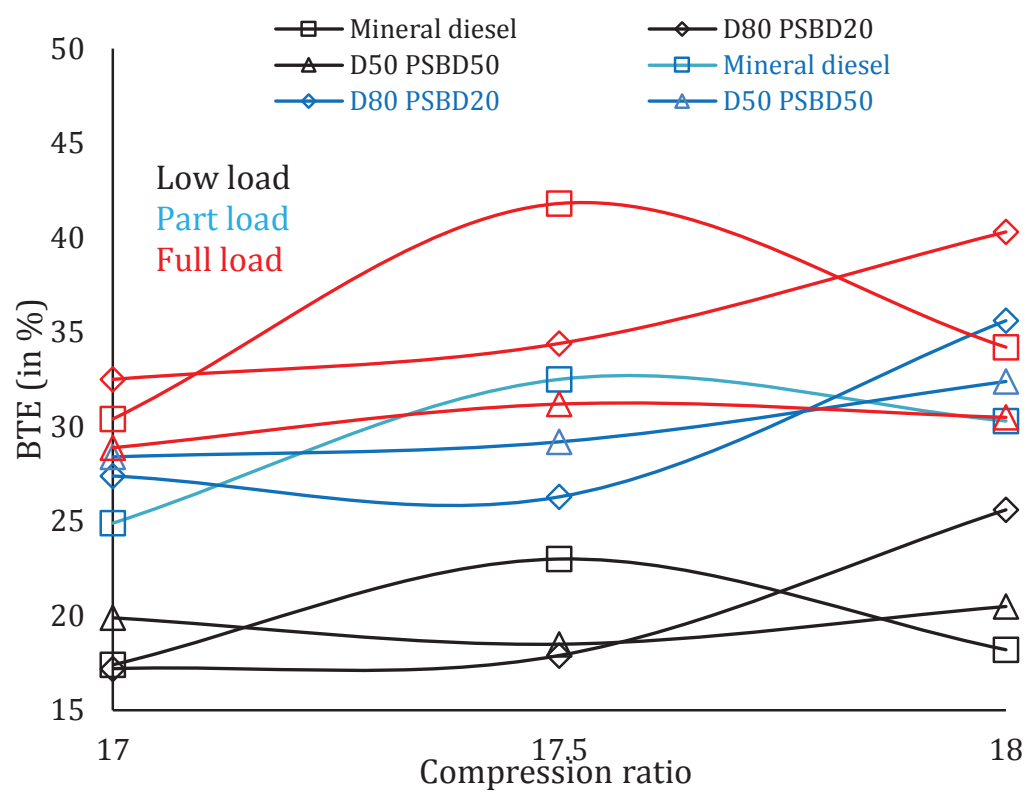

Fig. 3: Variation of BTE at various compression ratios. 
Later, as the compression ratio was changed to $18 \mathrm{CR}$, the whole process showed a significant effect. At low load conditions, BSFC of blended fuels were lesser compared to similar blends at other CRs. At full load condition, D80PSBD20 blend gave the low BSFC value as $0.25 \mathrm{~kg} / \mathrm{kWh}$ which was achieved with low calorific value and low density of D80PSBD20 fuel as listed in Table 1. D50PSBD50 blend consumed more fuel at full load conditions involving various compression ratios. This is due to lower calorific value and higher density leading to poor atomization resulting in poor performance of BSFC.

\section{Emission Characteristics}

CO emission: Carbon monoxide emission relates to the product of incomplete combustion. The pattern of $\mathrm{CO}$ emission under various compression ratios at different load condition is depicted in Fig. 5. At low load conditions, irrespective of the compression ratios, high $\mathrm{CO}$ emissions were observed which indicated the incomplete combustion process in the combustion chamber. The $\mathrm{CO}$ emission was lowered when increasing the load conditions up to part and full load condition. At 17.5CR, lowest $\mathrm{CO}$ value was observed as $0.025 \%$ for D80PSBD20 blend. D50PSBD50 had a slightly higher CO emission compared to D80PSBD20 blend at full load condition. All the $\mathrm{CO}$ emissions were still lesser compared to mineral diesel. On the other hand, at $17 \mathrm{CR}$, the values of $\mathrm{CO}$ were comparatively higher at all load conditions. This was due to higher combustion

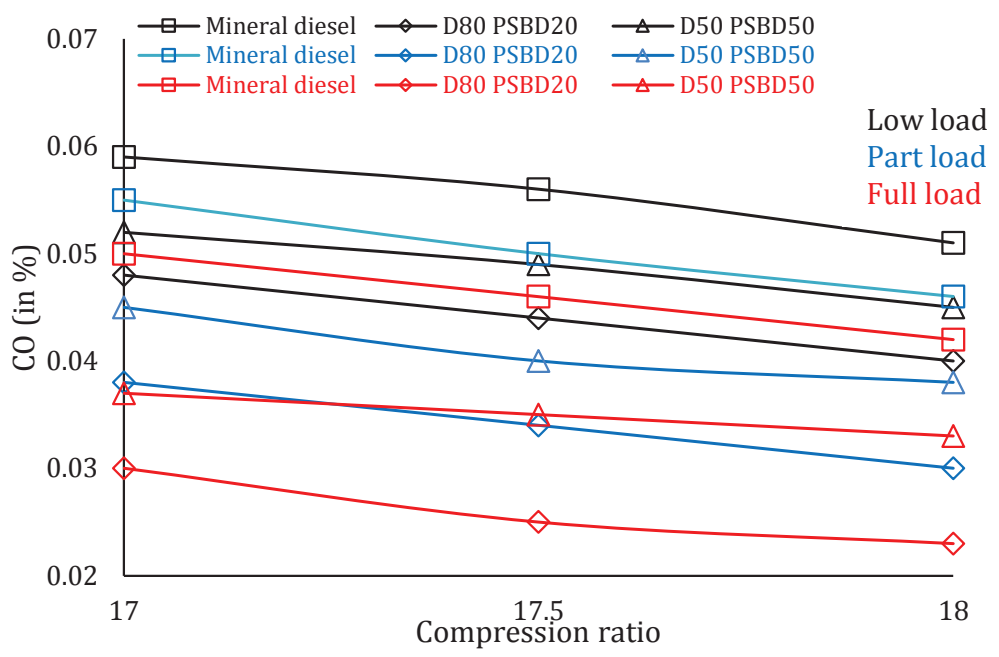

Fig. 5: Variation of $\mathrm{CO}$ emission at various compression ratios.

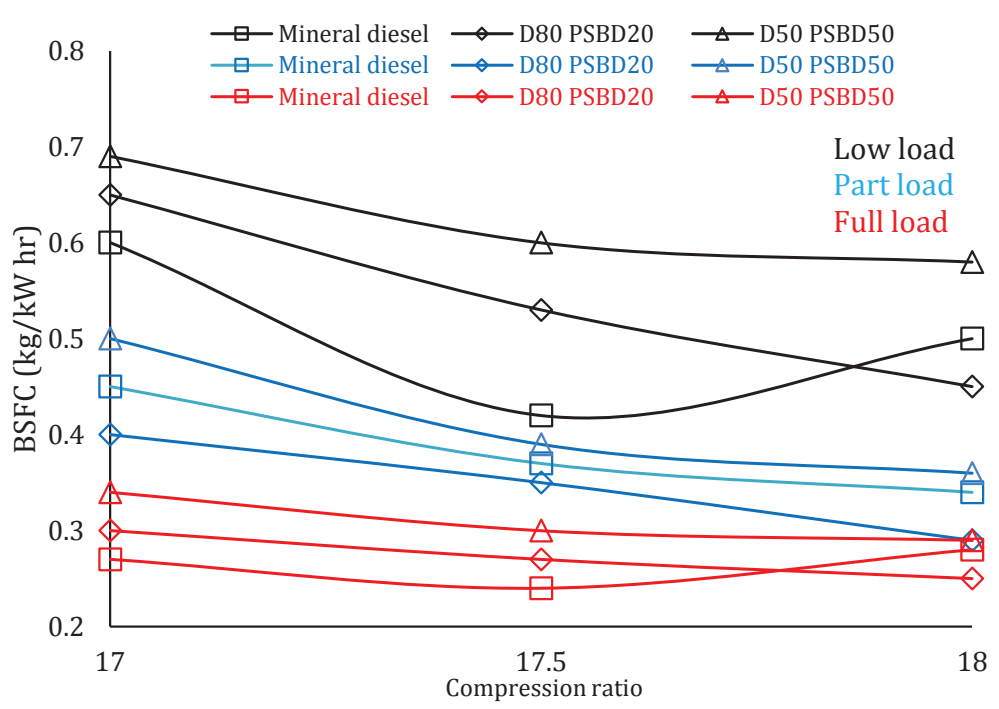

Fig. 4: Variation of BSFC at various compression ratios. 
volume available in the combustion chamber leading to poor combustion (Hariram et al. 2016). At 18CR, the minimum $\mathrm{CO}$ emission recorded was $0.023 \%$ at full load condition fuelled with D80PSBD20 blend. This is due to a comparatively effective combustion process within the cylinder. Other fuel blends reported higher $\mathrm{CO}$ values compared to D80PSBD20 blend. This was due to higher fuel density, oxygen shortage at high speed condition, insufficient heat in cylinder along with lesser time available to ensure complete combustion.

UBHC emission: Due to low combustion temperature and nature of fuel mixture, i.e. lean or rich, unburned hydrocarbons are released from the VCR DI CI engine. The unburned hydrocarbon (UBHC) emission of all tested blends under various compression ratios at different load conditions is presented in Fig. 6. In general, it was observed that irrespective of compression ratios, D80PSBD20 blend gave the lowest UBHC emissions at varied loading conditions. At 17.5CR, D50PSBD50 blend had a higher UBHC value which represents insufficient combustion due to low combustion temperature inside the combustion chamber. Higher UBHC emission was observed for mineral diesel which may be due to poor atomization and volatility nature of the fuel. At 17CR, all fuel blends had a higher value of UBHC emissions compared to $17.5 \mathrm{CR}$ at all load conditions which again portrayed the insufficient combustion temperature prevailing inside the combustion chamber. The UBHC emissions were higher at low load conditions for all three fuel blends. By increasing the loading conditions, the UBHC emissions reduced. Similarly, by increasing the compression ratios to $18 \mathrm{CR}$, the $\mathrm{UBHC}$ emissions reduced at all loading conditions. This was due to high combustion temperature, high cylinder pressure, high atomization and perfect air-fuel mixture. D50PSBD50 blend achieved lower UBHC emission as 78ppm at 18CR. But still was higher compared to D80PSBD20 blend UBHC emission. This was due to higher density and lower viscosity of the D50PSBD50 fuel blend.

$\mathrm{NO}_{\mathrm{x}}$ emission: The $\mathrm{NO}_{\mathrm{x}}$ emissions for all compression ratios at different load conditions are represented in Fig. 7. Nitrogen oxide was produced due to oxidation inside the cylinder as a result of high temperature. Oxygen content and in-cylinder temperature were the main factors to produce $\mathrm{NO}_{\mathrm{x}}$. Irrespective of the loading conditions, D80PSBD20 produced the highest $\mathrm{NO}_{\mathrm{x}}$ emissions among the tested fuel blends. $\mathrm{NO}_{\mathrm{x}}$ emission increased from no load to full loading conditions as the combustion chamber temperature increased due to complete combustion. $\mathrm{NO}_{\mathrm{x}}$ emission was observed to increase with an increase in CRs. The reason for lower emissions at 17CR was due to fall in combustion pressure and temperature inside the combustion chamber. The reason for mineral diesel and D50PSBD50 producing lower $\mathrm{NO}_{\mathrm{x}}$ was lack of oxygen content present inside the combustion chamber. The $\mathrm{NO}_{\mathrm{x}}$ emissions increased with increase in CR as prevailing conditions in the combustion chamber increased temperature. But, D80PSBD20 blend displayed a significant increase in $\mathrm{NO}_{\mathrm{x}}$ emissions due to increased compression ratio leading to better combustion resulting with an increase in in-cylinder temperature. On the other hand, D50PSBD50 blend produced the minimum $\mathrm{NO}_{\mathrm{x}}$ emissions (at part load $765 \mathrm{ppm}$ and full load condition 758ppm) as higher density

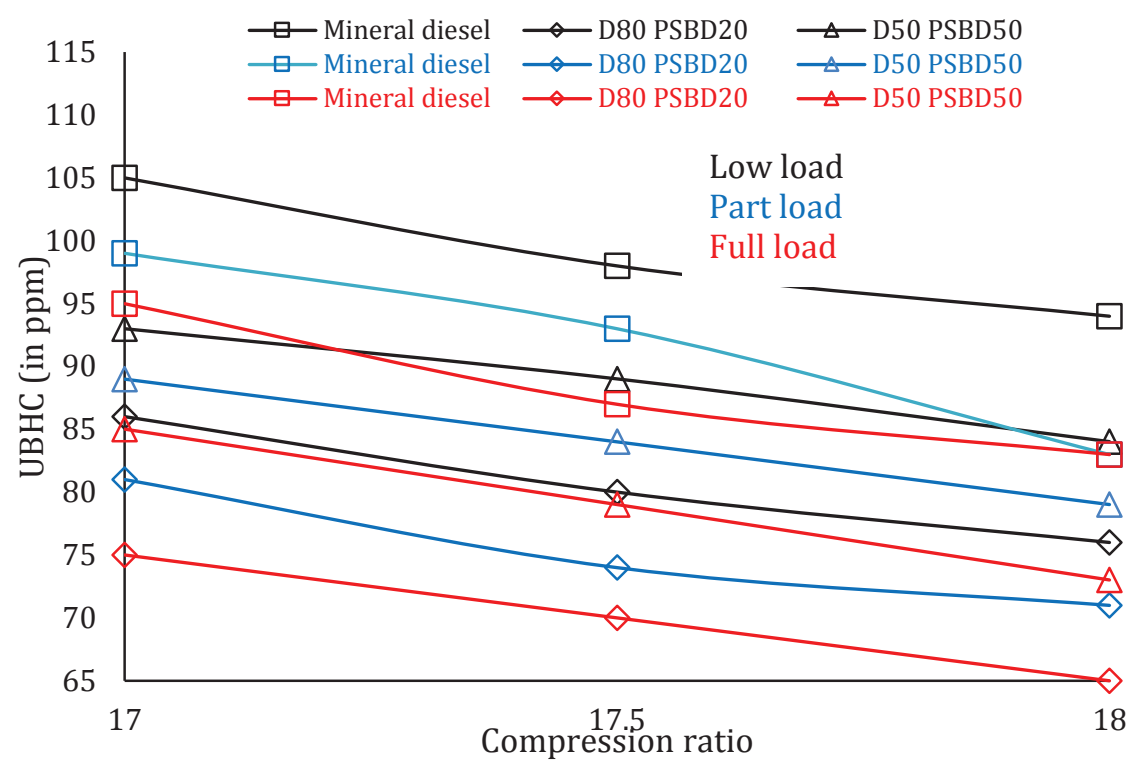

Fig. 6: Variation of UBHC emission at various compression ratios. 
along with slightly lower calorific value resulted with reduced the in-cylinder temperature (Anand et al. 2011).

$\mathrm{CO}_{2}$ emission: The variations of $\mathrm{CO}_{2}$ emission for various compression ratios at different load conditions are highlighted in Fig. 8. $\mathrm{CO}_{2}$ emission was derived as a product of complete combustion in the combustion chamber.

Significantly at $17.5 \mathrm{CR}$, the $\mathrm{CO}_{2}$ emission was investigated at low load, part load and full load fuelled with mineral diesel, D80PSBD20 and D50PSBD50. At low load condition, the diesel produced high $\mathrm{CO}_{2}$ emission compared to other fuel blends. Upon increasing the load, $\mathrm{CO}_{2}$ emissions of these three blends increased in the same pattern and the diesel fuel produced the maximum $\mathrm{CO}_{2}$ emission as $580 \mathrm{~g}$ / $\mathrm{kWh}$. The escalation of $\mathrm{CO}_{2}$ emission for the diesel fuel was due to prevailing high temperature inside the cylinder and perfect air supplied into the combustion chamber. On decreasing the compression ratio to $\mathrm{CR} 17$, the $\mathrm{CO}_{2}$ emission of all tested fuels lowered at all load conditions. At low and part load conditions, $\mathrm{CO}_{2}$ emission was low due to insufficient oxygen content present inside the combustion chamber leading to incomplete combustion. But, higher $\mathrm{CO}_{2}$ emission was observed at full load condition for diesel

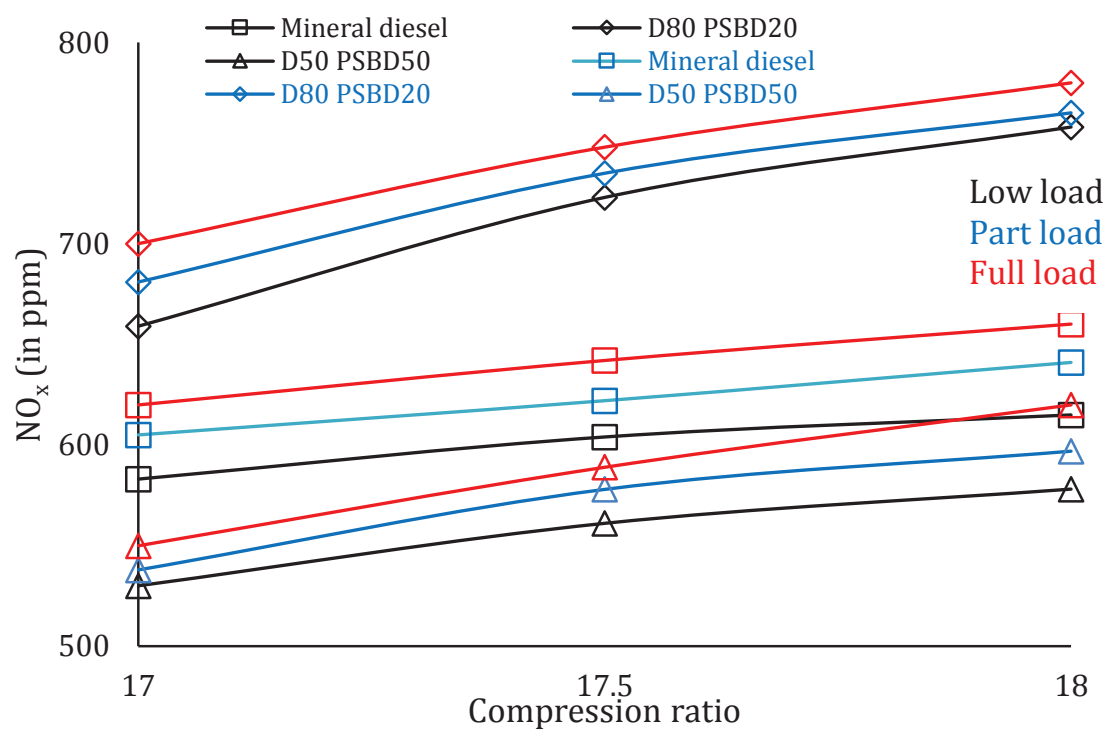

Fig. 7. Variation of $\mathrm{NO}_{\mathrm{x}}$ emission at various compression ratios.

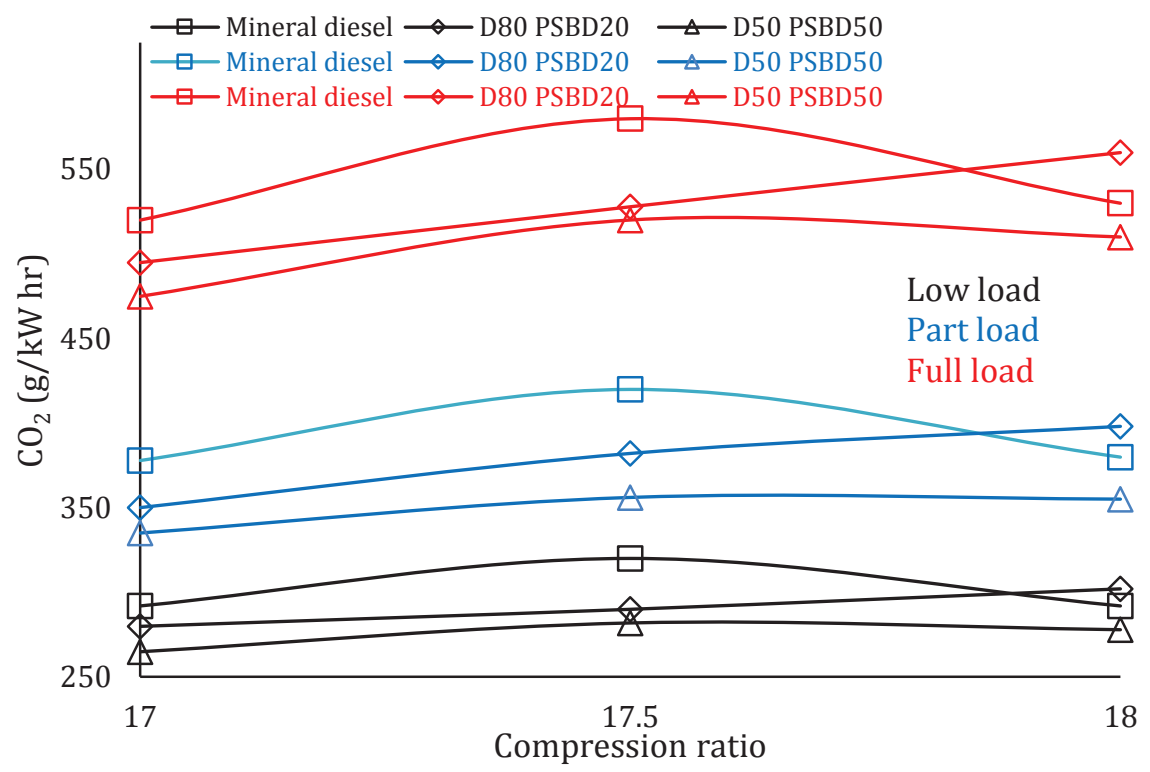

Fig. 8. Variation of $\mathrm{CO}_{2}$ emission at various compression ratios. 
fuel as $520 \mathrm{~g} / \mathrm{kWh}$. Lack of oxygen content, higher density and poor atomization process led the D50PSBD50 blend to produce lower $\mathrm{CO}_{2}$ emission. In general, D80PSBD20 fuel blend produced higher $\mathrm{CO}_{2}$ emissions at all maximum load conditions irrespective of compression ratios. At $18 \mathrm{CR}$, the $\mathrm{CO}_{2}$ emission reached the maximum value for D80PSBD20 fuel blend due to higher pressure created in the combustion chamber by this compression ratio leading to complete combustion.

Smoke emission: Fig. 9 denotes the smoke opacity for various compression ratios at different load conditions and fuel blends. In general, the smoke opacity declined with increase in compression ratios for biodiesel blends as well as diesel. Also, the soot emissions reduced with increase in loading conditions for all CRs. At 17.5CR, high smoke opacity was observed for mineral diesel at all load conditions.

On the other hand, D80PSBD20 showed the lowest smoke opacity values at all load conditions. The lower smoke opacity value was due to the availability of oxygen content in the cylinder leading to perfect combustion. At 17CR, the smoke opacity values were higher for all fuel blends with respect to 17CR. Similarly, smoke opacity values of all fuel blends were lesser at 18CR at all load conditions compared to other CRs. At $18 \mathrm{CR}$, the volume of the combustion chamber decreased resulting with increased pressure in combustion chamber leading to better combustion. Diesel fuel produces high soot emissions at various load conditions and increasing the CR led to a slight reduction in soot formation. D80PSBD20 reduced the smoke emission significantly at all conditions and various compression ratios. D50PSBD50 blend produced comparatively a higher soot formation with respect to D80PSBD20. This was due to the blend's physiochemical property in terms of having a higher density and poor volatility leading to a high smoke emission from the engine (Hariram et al. 2017).

\section{CONCLUSION}

An attempt was made in the present experimental investigations to understand the capability of using palm stearin wax as a value-added feedstock for producing palm stearin biodiesel (PSBD). Single stage transesterification process was adopted based on the FFA content which yielded $92 \%$ of PSBD. The fuel blends namely D80PSBD20 and D50PSBD50 were tested in the CI engine and benchmarked with mineral diesel at CR17.5 at all loads. Investigations were carried out at compression ratios 18 and 17 under similar conditions and conclusions drawn from this study were listed below.

- D80PSBD20 showcased a higher BTE value as 40.3\% for CR18 tested at full load condition whereas mineral diesel exhibited BTE as $41.8 \%$ at part load conditions for CR17.5. D50PSBD50 blend exhibited poor BTE at all load conditions as well as at all compression ratios.

- Increase in engine load reduced the BSFC of all test fuels at all compression ratios. At full load condition, D80PSBD20 exhibited lower BSFC $(0.25 \mathrm{~kg} / \mathrm{kW} \mathrm{hr})$ for CR18 which was $10.72 \%$ lower than diesel. At part load, D80PSBD20 showcased BSFC as $0.35 \mathrm{~kg} / \mathrm{kWh}$ for CR17.5.

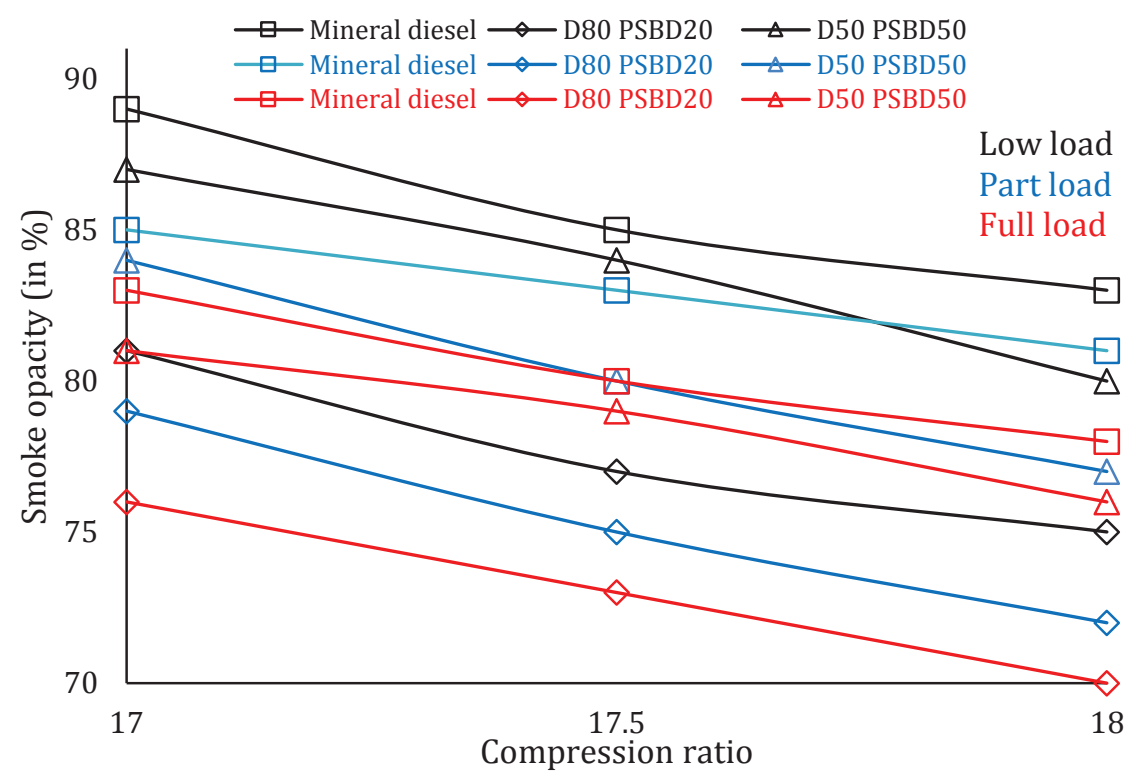

Fig. 9: Variation of $\mathrm{CO}_{2}$ emission at various compression ratios. 
- UBHC emission reduced significantly with an increase in compression ratios. D80PSBD20 exhibited lower UBHC emission (65ppm) for CR18 at full load condition. D80PSBD20 showcased a notable increase in UBHC emission around $6 \%$ to $8 \%$ as the $\mathrm{CR}$ was increased from 17 to 18 .

- Smoke and carbon-monoxide emissions showed a decreasing trend with the increase in compression ratios. At full load, D80PSBD20 emitted $0.025 \%$ of CO at CR17.5 whereas it reduced to $0.023 \%$ at CR18. On the other hand, reducing the compression ratio to $\mathrm{CR} 17$ increased the $\mathrm{CO}$ emission up to $0.030 \%$.

- $\mathrm{NO}_{\mathrm{x}}$ emission was observed at a higher level for all test fuels at CR18. D50PSBD50 produced lower $\mathrm{NO}_{\mathrm{x}}$ for CR17 at low and part load conditions.

\section{REFERENCES}

Ahmad, T., Danish, M., Kale, P., Geremew, B., Adeloju, S.B., Nizami, M. and Ayoub, M. 2019. Optimization of process variables for biodiesel production by transesterification of flaxseed oil and produced biodiesel characterizations. Renewable Energy, 139: 1272-1280.

Anand Kumar, S.A., Sakthinathan, G., Vignesh Radhakrishnan, Rajesh J Banu and Ala'a Al Muhtaseb 2019. Optimized transesterification reaction for efficient biodiesel production using Indian oil Sardine fish as feedstock. Fuel, 253: 921-929.

Anand, K., Sharma, R.P. and Pramod Mehta, S. 2011. Experimental investigations on combustion, performance and emissions characteristics of neat karanja biodiesel and its methanol blend in a diesel engine. Biomass and Bioenergy, 35(1): 533-541.

Anantha Kumar, S., Jayabal, S. and Thirumal, P. 2016. Investigation on performance, emission and combustion characteristics of variable compression engine fuelled with diesel, waste plastics oil blends. J. Braz. Soc. Mech. Sci. Eng., DOI: 10.1007/s40430-016-0518-6.

Arcaklioglu, E. and Celikten, I. 2005. A diesel engine's performance and exhaust emissions. Applied Energy, 80: 11-22.

Canakci, M., Erdil, A. and Arcakliogl, E. 2006. Performance and exhaust emissions of a biodiesel engine. Appl. Energy., 83: 594-605.

Cenk, Sayin., Metin and Gumus 2011. Impact of compression ratio and injection parameters on the performance and emissions of a DI diesel engine fuelled with biodiesel-blended diesel fuel. Appl. Therm. Eng., 31: 3182-3188.
Ganesh, R., Manikandan, K. and Jishu Chandran 2018. Emission analysis of palm stearin biodiesel fuelled diesel engine. International Journal of Ambient Energy, DOI:10.1080/01430750.2018.1517692.

Hariram, V. and Bharathwaaj, R. 2016. Application of zero-dimensional model for predicting combustion parameters of CI engine fuelled with biodiesel-diesel blends. Alexandria Engineering Journal, 55: 3345-3354.

Hariram, V. and Vasanthaseelan, S. 2015. Optimization of base catalysed transesterification and characterization of Brassica napus (canola seed) for the production of biodiesel. International Journal of ChemTech Research, 8(9): 418-423.

Hariram, V., Prakash, S., Seralathan, S. and Micha Premkumar, T. 2018. Data set on optimized biodiesel production and formulation of emulsified Eucalyptus teriticornisis biodiesel for usage in compression ignition engine. Data in Brief, 20: 6-13.

Hariram, V., Seralathan, S., Dinesh Kumar, M., Vasanthaseelan, S. and Sabareesh, M. 2016. Analysing the fatty methyl ester profile of palm kernel biodiesel using GC/MS, NMR and FTIR techniques. Journal of Chemical and Pharmaceutical Sciences, 9(4): 3122-3128.

Hariram, V., Seralathan, S., Kunal Bhutoria and Harsh, H. Vora. 2018. Experimental study on combustion and performance characteristics in a DI CI engine fuelled with blends of waste plastic oil. Alexandria Engineering Journal, 57: 2257-2263.

Hariram, V., Seralathan, S., Micha, P. and Penchala, T 2017. Reduction of exhaust emission using a nano-metallic enriched lemongrass biodiesel blend. energy sources, part A: Recovery. Utilization and Environmental Effects, 39(21): 2065-2071.

Hosamani, B.R. and Katti, V.V. 2018. Experimental analysis of combustion characteristics of CI DI VCR engine using a mixture of two biodiesel blends with diesel. Engineering Science and Technology, DOI: 10.1016/j. jestch.2018.05.015.

Mustafa Canakci, Ahmet Necati Ozsezen, Erol Arcaklioglu and Ahmet Erdil 2009. Prediction of performance and exhaust emissions of a diesel engine fuelled with biodiesel produced from waste frying palm oil. Expert Systems with Applications, 36: 9268-9280.

Praveena, V., Leenus Jesu Martin, M. and Edwin Geo, V. 2020. Effect of EGR on emissions of a modified DI compression ignition engine energized with Nano emulsive blends of grapeseed biodiesel. Fuel, 267: 117317.

Raheman, H. and Ghadge, S.V. 2007. Performance of compression ignition engine with mahua (Madhuca indica) biodiesel. Fuel, 86: 2568-2573.

Rosha, P., Mohapatra, S.K., Mahla, S.K., Cho, H., Chauhan, B.S. and Dhir, A. 2019. Effect of compression ratio on combustion, performance, and emission characteristics of compression ignition engine fuelled with palm (B20) biodiesel blend. Energy, 178: 676-684.

Saravanan, A., Murugan, M., Sreenivasa Reddy, M. and Satyajeet Parida. 2019. Performance and emission characteristics of variable compression ratio CI engine fuelled with dual biodiesel blends of rapeseed and mahua. Fuel, 263: 116751. 